\title{
Perceived Barriers and Levels of Satisfaction with Student Services for Adult Students
}

\author{
Nicole Cabrere-Buggs
}

Adult students face a multitude of issues when attending college and seeking assistance from student support services to succeed. Because of other responsibilities outside of their education, such as full-time jobs and family or household responsibilities, adult students have minimal access to these support services. This study was intended to investigate differences in level of satisfaction with student support services used by adults seeking a baccalaureate degree, and to examine the barriers faced by these students. The study examined situational, institutional, and dispositional barriers at one public research university, which may shed light on areas in student services which need to be addressed in higher education.

The adult population continues to rise in universities and colleges as a result of more and more students returning to school (Rooney, 2002). Consequently, adult students confront a multitude of issues when attending college and seeking assistance from student support services in their efforts to succeed. However, many adults can only attend college part-time due to full-time jobs and a variety of responsibilities at home. The major challenge facing these students is minimal access available to student support services. The outcomes of how adult students perceive student services at one southern, metropolitan research university are described in this research. Included are recommendations for administrators, faculty, and student services personnel concerning the reevaluation of structures currently in place.

Adults entering college seek special help in academic areas, child care services, and career planning, among other student services (Richardson \& King, 1998). Academic advising, course registration, and applying for financial aid are also important to adult students (Bowden \& Merritt, 1995). Support services such as these traditionally have been offered during daytime hours to meet the needs of traditional full-time students. However, many adults can only attend college part time due to fulltime jobs and a variety of responsibilities at home. Instead of changing programs and services to facilitate the adjustment for adult students, many institutions simply have expected adult students to adapt to programs or services currently in place (Thon, 1984). If the goal of many institutions of higher education is to meet the needs of adult students, barriers must be eliminated so that adults perceive all aspects of education as attainable (Cross, 1981).

Nicole Cabrere-Buggs (ncabrere@memphis.edu) is the coordinator for Orientation \& Recruitment Events in the Division of Academic Affairs at the University of Memphis. 
Cross (1981) includes the following elements when defining situational, institutional, and dispositional barriers:

"situational" barriers include cost of tuition, child care, home and job responsibilities, parking and security issues, cost of books, level of family support, amount of time required to study;

"institutional" barriers include amount of time required to complete program[s], courses not scheduled when one can attend, registration and bursar issues; faculty sensitivity, credit for life experiences; computer and lab facilities; academic advising; counseling for job placement, or personal issues; availability of tutorial services; information on programs and activities; financial aid and scholarship availability; and bookstore hours;

"dispositional" barriers include fear of competing with younger students, fear of success in college; feeling tired of the red tape and classroom requirements; feeling alienation on campus. (p. 99)

The primary purpose of this study was twofold. First, this study was intended to investigate differences in level of satisfaction with student support services used by adult students seeking a baccalaureate degree. Second, the study examined the barriers faced by those students. The study examined situational, institutional, and dispositional barriers which may shed light on which areas need to be addressed in higher education regarding student services at one public research university.

\section{Method}

\section{Participants}

This research focused on 447 adult students with undecided majors, ages 25 and older, at one southern, metropolitan research university. The total enrollment at this university is 20,465; at the time of the study $32 \%$ were adult students. The Institutional Research Office collects and retains statistical and demographic data of students enrolled at the university. This database was used to identify students who participated in the study. Of the 447 "undecided" students ages 25 and older enrolled, 56\% of the students were enrolled part time and $43 \%$ were enrolled full time. Of 447 students asked to participate, 160 were freshmen, 136 were sophomores, 84 were juniors, and 67 were seniors. The students were surveyed during the 2004 spring semester.

\section{Survey}

Authored by Whitmer (1998) and used with her permission, the questionnaire covered items identified by Cross (1981) as situational, institutional, and dispositional barriers. 
The survey instrument identified three sections: barriers, student support services, and demographic information. The reliability analysis conducted by Whitmer (1998) indicated coefficients of internal consistency ranging from 0.64 to 0.78 . This survey was specifically designed to obtain data needed to describe and assess barriers, satisfaction of student support services, and demographics of adult students (Whitmer, 1998).

In Section I-Barriers (questions 1-18), perceptions of barriers faced by undergraduate students completing degrees are measured by using a 4-point Likert scale, with 1) Not a problem; 2) Minor problem; 3) Average problem; 4) Overwhelming problem.

In Section II—Student Support Services (questions 19-37), perceptions of satisfaction with available student support services are measured by using a 5-point Likert scale. The Likert scale includes: 1) Never used; 2) Very dissatisfied; 3) Dissatisfied; 4) Satisfied; 5) Very satisfied.

Section III-Demographic Information (questions 38-43), collects data on gender, dependencies, and ethnicity. For anonymity purposes, students will not be required to identify data that includes name, Social Security number, or home address. The survey used in this research is included in the Appendix.

\section{Statistical Analysis}

The Statistical Package for the Social Sciences (SPSS) software program was used to analyze the data. All questions were analyzed using t-tests to determine if there were differences between the full-time and part-time students. An alpha $=0.05$ significance level was used to make all comparisons, and descriptive statistics were used to analyze all demographic and survey items.

\section{Results}

\section{Demographic Data}

Of 447 "undecided" adults in the population, the final sample consisted of 100 full-time and 126 part-time adult students. Approximately $64 \%$ of the population was female, while $36 \%$ of the population was male. More than $45 \%$ of the respondents reported marital status as divorced or separated and $35 \%$ reported having no children under 18 years old at home.

\section{Barriers to Participation}

Cross's study (1981) defined three levels of barriers that impede participation among adult students-situational, institutional, and dispositional. Barriers that can occur at any time are described as situational barriers. Lack of time and money and/or added career-related or family responsibilities can prevent adult students from full immersion in the college experience. A combination of these circumstances can be beyond the 
student's control. Institutional barriers, which include a lack of understanding of structures, rules, and regulations in programs and services, can further impede participation. Dispositional barriers relate to confidence, past experiences, and a perception one has in regard to learning

Institutional Barriers. Findings showed no significant difference in regard to institutional barriers $(p=0.052)$ for part-time and full-time students. Results indicated that part-time and full-time students perceived almost all barriers equally. However, survey items such as item 4$)$ courses scheduled when I can attend $(M=2.45)$; item 5) amount of time required to complete a degree program $(M=2.41)$; item 8$)$ availability of financial aid and scholarship money $(M=2.84)$; and item 15$)$ advising $(M=2.63)$ demonstrated slightly higher means for part-time students. Most of the part-time students attended college at night or at weekends when many of these services listed were not available.

Overall, many adult students considered availability of financial aid and scholarship money a problem (part-time: $n=126, M=2.74$; full-time: $n=100, M=2.84$ ). In reviewing these findings, it is important to note the lack of scholarship and financial aid available specifically for adult students in general. Moreover, there are even fewer aid opportunities available for part-time adult students.

Dispositional barriers. Substantially higher means were found in all dispositional barriers faced by full-time adult students. Schlossberg, Lynch, and Chickering (1989) indicated that adults often feel a sense of not belonging on college campus. The feeling of being marginalized may be connected to this perception for full-time adult students. Although full-time students indicated this barrier at a higher rate than part-time students, the sense of marginality may be shared by all adult students as well.

Situational barriers. This research found no significant differences among the perceived effects of situational barriers among part-time and full-time students. However, it should be noted that several of the barriers classified as situational were found as "average" and "minor" problems by some adult students. The cost of tuition (44\%); availability of child care (63.3\%); and time to handle all responsibilities $(55.8 \%)$, work responsibilities $(87.6 \%)$, and home responsibilities $(60.6 \%)$ were high percentages for "minor" problems. Level of family support (73.5\%) and parking and security $(54.9 \%)$ also were found as high percentages for "average" problems. More importantly, results indicated that most adult students did not use disability resources $(95.1 \%)$ and bursar office hours $(56.6 \%)$.

\section{Student Support Services}

Differences also were found in comparing overall levels of satisfaction and perceived effects of barriers for both part-time and full-time adult students. $T$-tests results demonstrated significant differences among both populations. More specifically, both part-time and full-time students were satisfied with the support services despite the levels of problems they might have faced with the services. These data support Cross's (1981) research which indicated that adults participate in educational opportunities due to 
convenience.

The findings also showed that, regardless of classification, a majority of students failed to use the services available. Over $90 \%$ of the students failed to use job placement, credit for experiential learning, counseling and testing to help decide on a major, disability resources, legal assistance, intramural gym hours, and activities for adult students. Reasons for not using these services might include inconvenient hours, dissatisfaction with services as a result of prior experiences, or lack of knowledge about the services.

Although adult students indicated that the accessibility of some support services was a problem, overall they were generally satisfied with the services received. Findings in this study demonstrated that there was not a difference among the levels of satisfaction with student support services among part-time and full-time adult students. Substantial percentages showed that many respondents were satisfied with academic support services offices $(85.8 \%)$, remedial assistance in college subjects $(78.8 \%)$, academic advising (76.5\%), and information about student support services $(82.3 \%)$. The results regarding academic advising conflicted slightly with Crocket's (1984) arguments concerning the challenges that undecided students face with academic advising.

\section{Discussion and Recommendations}

\section{First-Year Orientation Course}

One finding of this study suggests that adult students do not use many of the student services available. A first-year orientation course is an effective strategy that has been implemented at many universities and has provided students with the necessary skills to become successful in college (Braxton \& Mundy, 2001; Crissman, 2001). The institution mentioned in this study has also implemented a freshmen orientation course; however, this class is not mandatory for all students.

Despite the many support services available at the institution researched, results demonstrate that many adult students reported having little or no experience using many them. Lack of usage may be due to a lack of knowledge. Information about and referral to student services generally is a key component of extended orientation courses or first-year seminars. Knowing this information could minimize and eliminate the many institutional barriers faced by undecided adult students. Additionally, connections to faculty, staff, and other students can be fostered in these types of classes. Required enrollment for adult students returning to or starting college for the first time should be investigated.

\section{Allocation of Funds}

Higher education administrators should ensure that their services are current and available for all students. Specifically, administrators should allocate funding to ensure that adult students can equally access support services during nontraditional hours. 
A problem in many institutions is that instead of changing programs and services to facilitate the adjustment for adult students, many colleges have simply expected adult students to adapt to the programs or services currently in place (Thon, 1984).

\section{Financial Opportunities}

Approximately $43 \%$ of students in this study expressed concern for limited availability of financial aid and scholarships. This particular school awards first-year academic scholarships to traditional age students recently graduated from high school. This university has currently established an adult scholarship; however, funding is limited. Furthermore, few or no institutional scholarships are available for part-time adults. Creating additional institutional financial aid and scholarships for adult students would provide more opportunities to help adult students succeed.

\section{Adult Student Support Services}

Feelings of unconnectedness can lead to dissatisfaction and may result in missed opportunities with faculty, staff, and support services. Contact with faculty and staff in higher education has proven to be influential in students' decisions to remain in college (Chickering \& Gamson, 1987; Glennen, Farren, \& Vowell, 1996). The Office of Adult and Commuter Student Services historically has served as the main support service for adult students. Although this institution has designated a specific office to address the needs of adult students, results from this study show that some of these students feel unconnected with the campus as found in similar studies (Schlossberg, Lynch, \& Chickering, 1989).

By reevaluating the current methods of reaching the adult student population through this office, barriers can be minimized. Reconsidering the location, office hours, and structure of the office may help bridge the gap for many adult students who are unaware of the services offered by the institution. Restructuring may also help to understand prior experiences or future experiences that may lead to dissatisfaction.

\section{Evening and Weekend Support Services}

As mentioned, results of the study show that many services were never used by many of the adult students surveyed. The assumption of available online access should not necessarily be the solution. As mentioned in Chapter 2, many adult students are not advanced in technology use and online access (Lenhart, 2000). Adult students may not be using campus resources because they don't know about them. It is important to take into account that many full-time and part-time adult students attend courses during nontraditional hours, making it difficult for them to access many of the student support services available during weekday hours. Therefore, administrators should consider conducting a needs assessment to evaluate the current availability of services during the evening and weekend, and to assess adults' knowledge of technology. 
Currently, this university employs several nighttime accessible services, and few weekend services. Since the research suggests that there is a positive relationship between the utilization of support services, it is important to increase the access for all students (Pasacrella \& Terenzini, 1991).

\section{Limitations}

Data were gathered from a single doctoral university at one particular time in the 2004 spring semester. Therefore, results from this analysis should be generalized with caution. Furthermore, due to the large number of potential participants, the population involved in this study focused only on "undecided" adult students. Sample size and selection of classification need to be taken in consideration when generalizing these findings.

\section{Conclusions}

Overall, more studies on adults have demonstrated that participation on campus has been one of the strongest factors in student persistence and success when comparing other factors such as age, race, income, employment status, high school academics, and marital status (Friedlander \& MacDougall, 1992; Tinto, 1993; Whitmer, 1998). The findings support past research (Cross, 1981; Hockenberger, 1991; Zamanou, 1993) in that there are still barriers among the student support services adults use at higher education institutions. Findings show restructuring is needed in many support service areas to disseminate barriers adults face (Bowden \& Merritt, 1995; Richardson \& King, 1998).

This study also prompts a number of possibilities for future research concerned with satisfaction of the student support services for adult students. Administrators of student support services should be asked to evaluate the current practices and methods in place to see if needs of adults are being met.

\section{References}

Astin, A. W. (1993). What matters in college? Four critical years revisited. San Francisco: Jossey-Bass.

Bowden, R., \& Merritt, R., Jr. (1995). The adult learner challenge: Instructionally and administratively. Education, 115 (3), 426-431.

Braxton, J. M., \& Mundy, M. E. (2001). Powerful institutional levers to reduce college student departure. Journal of College Retention, 3(1), 91-118.

Chickering, A. W., \& Gamson, Z. F. (1987). Seven principles for good practice in undergraduate education. AAHE Bulletin, 39(7), 3-7. 
Crissman, J. L. (2001). The impact of clustering first-year seminars with English composition courses on new students' retention rates. Journal of College Student Retention: Research, Theory, and Practice, 3(2), 137-152.

Crockett, D. S. (Ed.). (1984). Advising skills, techniques, and resources. Iowa City, IA: The American College Testing Program.

Cross, K. P. (1981). Adults as learners: Increasing participation and facilitating learners. San Francisco: Jossey-Bass.

Friedlander, J., \& MacDougall, P. R. (1992). Achieving student success through student involvement. Community College Review, 20(1), 20-28.

Glennen, R. E., \& Vowell, F. N. (Eds.). (1995). Academic advising as a comprehensive campus process. National Academic Advising Association Monograph Series (No. 2).

Hockenberger, S. J. (1991). Relationship of instructional mission and goals to barriers and opportunities experienced by nontraditional students in private liberal arts colleges. Unpublished doctoral dissertation, George Peabody College for Teachers of Vanderbilt University.

Lenhart, A. (2000, December 4). Who's not online? The Digital Divide Network. Retrieved February 20, 2004, from http://www.digitaldivide.net/articles/ view.php?ArticleID=349

Pasacarella, E. T. (1991). The impact of college on students: The nature of the evidence. Review of Higher Education, 14, 453-466.

Richardson, J. T. E., \& King, E. (1998). Adult students in higher education: Burden or boon? Journal of Higher Education, 69(1), 65-88.

Rooney, M. (2002, November 1). A surge of students: Enrollments soar at colleges of all types. For some of them, that's a mixed blessing. The Chronicle of Higher Education, p. A33.

Schlossberg, N. K., Lynch, A. Q., \& Chickering, A. W. (1989). Improving higher education environments for adults. San Francisco: Jossey-Bass.

Thon, A. J. (1984). Responding to the non-academic needs of adult students. NASPA Journal, 21(4), 28-34.

Tinto, V. (1993). Leaving college: Rethinking the causes and cures of student attrition (2nd ed.). Chicago: University of Chicago Press.

Whitmer, S. K. (1998). A study comparing two programmatic approaches for nontraditional and undergraduate students with emphasis on barriers encountered and support services utilized. Unpublished doctoral dissertation, University of Louisville, Louisville, Kentucky.

Zamanou, S. (1993). Differences do make a difference: Recruitment strategies for the nontraditional student. Paper presented at the annual meeting of the Speech Communication Association, Miami Beach, FL. (ERIC Document Reproduction Service No. ED367034) 


\section{Survey}

Instructions: Please complete entire survey. SELECT THE RESPONSE THAT MOST CLOSELY CORRESPONDS WITH YOUR CHOICE. DO NOT WRITE YOUR NAME OR ADDRESS ON

THE SURVEY. Please answer all questions AND return the survey in the enclosed envelope.

\section{Levels of Problem:}

1. Not a Problem

2. Minor Problem

3. Average Problem

4. Overwhelming Problem

\section{BARRIERS:}

1. Cost of tuition

2. Child care

3. Fear of competing with younger students

4. Courses not scheduled when I can attend

5. Amount of time required to complete the program

6. Time to handle all my responsibilities

7. Class attendance requirements

8. Availability of financial aid and scholarship money

9. Level of family support

10. Fear concerning ability to succeed in college

11. Registration

12. Feeling a part of the university

13. Work responsibilities

14. Parking and security issues

12

2

3

4

$\begin{array}{llll}1 & 2 & 3 & 4\end{array}$

1

2

34

$\begin{array}{llll}1 & 2 & 3 & 4\end{array}$

$\begin{array}{llll}1 & 2 & 3 & 4 \\ 1 & 2 & 3 & 4\end{array}$

\section{1}

2

3

4

$\begin{array}{lll}2 & 3 & 4\end{array}$

$2 \quad 3 \quad 4$

$\begin{array}{lll}2 & 3 & 4\end{array}$

$2 \quad 3 \quad 4$

$2 \quad 3 \quad 4$

$\begin{array}{lll}2 & 3 & 4\end{array}$




\begin{tabular}{|c|c|c|c|c|}
\hline 15. & Advising & 1 & 2 & 3 \\
\hline 16. & Home responsibilities & 1 & 2 & 3 \\
\hline 17. & Faculty sensitivity & 1 & 2 & 3 \\
\hline 18. & Credit for life experiences & 1 & 2 & 3 \\
\hline
\end{tabular}

\section{STUDENT SUPPORT SERVICES}

Listed below are services provided on campus. Please answer all questions.

\section{Levels of Satisfaction:}

1. Never used

2. Very dissatisfied

3. Dissatisfied

4. $\quad$ Satisfied

5. $\quad$ Very Satisfied

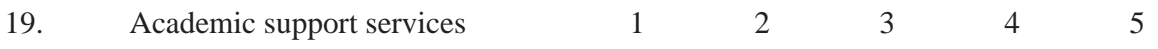

$\begin{array}{lllllll}\text { 20. Job placement assistance } & 1 & 2 & 3 & 4 & 5\end{array}$

$\begin{array}{lllllll}\text { 21. Personal counseling } & 1 & 2 & 3 & 4 & 5\end{array}$

$\begin{array}{lllllll}\text { 22. Library hours } & 1 & 2 & 3 & 4 & 5\end{array}$

23. Computer lab hours and assistance

$\begin{array}{lllll}1 & 2 & 3 & 4 & 5\end{array}$

24. Bookstore hours

$\begin{array}{lllll}1 & 2 & 3 & 4 & 5\end{array}$

25. Remedial assistance

in college subjects

26. Credit for experiential learning

$\begin{array}{llllll}1 & 2 & 3 & 4 & 5\end{array}$

27. Counseling/testing to help decide a major

28. Academic advising

$\begin{array}{lllll}1 & 2 & 3 & 4 & 5\end{array}$

29. Information about support services

$\begin{array}{llllll}1 & 2 & 3 & 4 & 5\end{array}$

30. Telephone registration

$\begin{array}{llllll}1 & 2 & 3 & 4 & 5\end{array}$




\begin{tabular}{|c|c|c|c|c|c|}
\hline 31. & Parking facilities & 1 & 2 & 3 & 4 \\
\hline 32. & Security mechanisms & 1 & 2 & 3 & 4 \\
\hline 33. & Disabilities resources & 1 & 2 & 3 & 4 \\
\hline 34. & Bursar office hours & 1 & 2 & 3 & 4 \\
\hline 35. & Legal assistance & 1 & 2 & 3 & 4 \\
\hline 36. & Intramural gym hours & 1 & 2 & 3 & 4 \\
\hline 37. & $\begin{array}{l}\text { Activities for adult } \\
\text { students }\end{array}$ & 1 & 2 & 3 & 4 \\
\hline
\end{tabular}

\section{DEMOGRAPHIC INFORMATION:}

Demographic information is essential to this study so PLEASE ANSWER ALL QUESTIONS. DO NOT INCLUDE YOUR NAME SOCIAL SECURITY NUMBER, BIRTH DATE, OR OTHER IDENTIFYING DATA.
38. Gender:
(1) Male
(2) Female
39. Age:
(1) $17-24$
(2) $25-34$
(3) 35 and above
40. Marital status:
(1) Unmarried
(2) Married
(3) Divorced/Separated
(4) Widow/Widower

41. Number of dependent children at home (18 yrs. \& under):
(1) 0
(2) 1
(3) 2
(4) 3
(5) $4+$ 